\title{
Effectiveness of zinc oxide nanoparticles against helminthiasis: a preliminary investigation conducted on Pheretima posthuma
}

\author{
Faruk Hosain $^{\text {a }}$, Md Shafiul Islam ${ }^{a}$, Abdullah Al Ragib ${ }^{a, b^{*}}$, Muhammad Zukaul Islam ${ }^{\mathrm{c}}$ and \\ Tariqul Islam ${ }^{\mathrm{d}}$
}

${ }^{a}$ Department of Applied Chemistry and Chemical Engineering, Noakhali Science and Technology University, Noakhali-3814, Bangladesh

${ }^{b}$ School of Chemical Engineering and Technology, Tianjin University, Tianjin 300350, China

${ }^{c}$ Department of Chemistry, Bangladesh University of Engineering and Technology, Dhaka-1000, Bangladesh

${ }^{d}$ Faculty of Pharmacy, International Islamic University Malaysia, 25200 Kuantan, Pahang, Malaysia

\section{H R O N I C L E}

\begin{tabular}{l}
\hline Article history: \\
Received June 1,2020 \\
Received in revised form \\
June 26,2020 \\
Accepted July 28, 2020 \\
Available online \\
July 28, 2020 \\
\hline Keywords: \\
ZnO nanoparticles \\
Antihelminthic potential \\
Pheretima posthuma \\
Paralyzed time \\
Death time
\end{tabular}

\section{Introduction}

The field of technological application of nanoparticles called nanotechnology plays a significant role directly or indirectly in human civilization, which encompasses science, engineering, and the technology involves not only nanometer-sized materials but also devices and systems at the nano-size level. The interest for nanoparticles has increased in the past years due to their pliability in structure, size, biocompatibility, high surface area, and versatile functionalization, which have led to their universal application in diverse areas. Because of the wide range of applications, metal oxide NPs have appeared great attention. ${ }^{1}$ Before using the nanoparticles of inorganic metal oxide such as $\mathrm{TiO}_{2}, \mathrm{CaO}$, $\mathrm{ZnO}, \mathrm{MgO}$, etc. it is necessary to ensure its safety, toxicity and biocompatibility to human beings ${ }^{2,3}$ and recently scientists identified and regarded those as a safe material for human health, especially $\mathrm{MgO}$ and $\mathrm{CaO}$ are essential because of minerals source of the human body. ${ }^{4-7}$ 
$\mathrm{ZnO}$ NPs are one of the most reliable, unique and versatile important material both in the form of ceramic or powder. This form exhibits several outstanding characteristics such as optical transparency, electric dynamism and potential, piezoelectric effect, nonpoisonous, wide accessibility, economical and stability. ${ }^{8,9}$ Nanostructure (intermediate size between microscopic and molecular structure) $\mathrm{ZnO}$ can be applied in various fields for its numerous characteristics such as high frequency filtering application (surface acoustic wave device) ${ }^{10}$, photocatalysis reaction ${ }^{11}$, photodetectors $^{12}$, varistors ${ }^{13}$, solar cells ${ }^{14}$, biosensors $^{15}$, gas sensors ${ }^{16}$, nanogenerator ${ }^{17}$, ultraviolet nanolasers ${ }^{18}$ etc. The interest for $\mathrm{ZnO}$ has grown over the years since it has been shown to have unique properties which can be easily applied in case of biomedical application such as antibacterial, antifungal, anticancer agent (drug delivery) and also applicable in different industrial application for example superior catalytic, UV filtering properties and photochemical activity. Different availability morphologies of $\mathrm{ZnO}$ nanostructure have appeared as nanorods, nanosphere, nanowires, nanotubes (dimension less than $100 \mathrm{~nm}$ ), nanoneedles, nanorings have been easily synthesized. ${ }^{19}$ Recently, many methods are being applied to prepare the various nanostructures of $\mathrm{ZnO}$. Last decade researchers tried to establish different synthesis methods and recently different modified synthesis techniques have been established for ZnO NPs such as chemical vapor transport (CVT) techniques ${ }^{20,21}$, sol-gel method ${ }^{22}$, direct precipitation (low temperature) and coprecipitation (room temperature) synthesis ${ }^{23-25}$, sonochemical or microweb assisted synthesis ${ }^{26,27}$, RF plasma synthesis ${ }^{28}$, hydrothermal process ${ }^{29}$ etc. To synthesize ZnO NPs into various complicated structures such as floweret style and web (network) type conglomerates can be prepared from developed physical vapor transport (vacuum deposition) and chemical vapor deposition (surface modification) method. ${ }^{23}$ Besides, various steps, complicated equipment, and high temperature are normally required for these methods, but on the contrary, most cost-effective, simple and easy to make a change in a specific size and able to be scaled in some of the methods are precipitation, hydrolysis and hydrothermal process that all are expressed in low-temperature wet chemical processes. ${ }^{23}$

In this investigation, zinc nitrate hexahydrate $(\mathrm{Zn}(\mathrm{NO} 3) 2.6 \mathrm{H} 2 \mathrm{O})$ and sodium hydroxide $(\mathrm{NaOH})$ were used without any posterior treatment by low reaction temperature to synthesize ZnO NPs with the help of applying knowledge of simple precipitation and sonochemical process. But some instrumental modification was added to run the synthesis in a cheap, simple, better and easy way in which the configuration and dimension of the ZnO NPs were estimated by Scanning Electronic Microscopy (SEM). Apart from this, ZnO NPs were used as a test sample and examined to identify the anthelmintic activity on Pheretima posthuma (earthworm). Parasitic helminths not only affect animals but also man and causing considerable hardship which infections spread throughout the world and inhibit the growth and also responsible for huge economic losses. ${ }^{30,31}$ Overall, it may be said that the antihelminthic effect might be due to the creation of reactive oxygen species (ROS) which affects and targets different macromolecules. ${ }^{31}$ So different medicine has been progressed from the last decade by scientists, pharmacists, and doctors to treat this. But in this big issue, the availability of effective medicine can fight to solve the crisis ${ }^{30}$ In this investigation, we evaluated the antihelminthic activity of ZnO NPs against Pheretima posthuma in which paralyzed time as well as mortality time activity was marked perfectly to understand the result with the ZnO NPs.

\section{Experimental}

\subsection{Chemical reagents and Instruments}

Analytical grade $\left(98 \%\right.$ AR) zinc nitrate hexahydrate $\left(\mathrm{Zn}\left(\mathrm{NO}_{3}\right)_{2} .6 \mathrm{H}_{2} \mathrm{O}\right)$, sodium hydroxide $(45 \%$ AR $\mathrm{NaOH}$ ), deionized water, saline water, carboxymethylcellulose (CMC), were purchased from Loba Chemie Co. (India). Albendazole (400 mg/tablet) was purchased from the local market. SEM (Hitachi S-3400, Hitachi, Japan), UV spectrophotometer (1650 PC, Shimadzu, Japan), weighing machine (AGN 220C, AXIS, Poland), etc. were also used. 


\subsection{Synthesis}

The $\mathrm{ZnO}$ nanoparticles (NPs) were prepared according to a simple low reaction temperature precipitation and sonochemical process ${ }^{32,33}$, but some modifications were added in this experiment. Firstly, at room temperature $0.5 \mathrm{M} \mathrm{Zn}\left(\mathrm{NO}_{3}\right)_{2} .6 \mathrm{H}_{2} \mathrm{O}$ solution was prepared by dissolving it in $100 \mathrm{ml}$ deionized water and $1.0 \mathrm{M} \mathrm{NaOH}$ solution was also prepared by dissolving it in $200 \mathrm{ml}$ deionized water. Both of the solutions were freshly prepared and used immediately. All the chemicals were used in this experiment, $\mathrm{NaOH}$ and $\mathrm{Zn}\left(\mathrm{NO}_{3}\right)_{2} \cdot 6 \mathrm{H}_{2} \mathrm{O}$ were of analytical grade $(98 \% \mathrm{AR})$ and utilized without any further treatment. Sodium hydroxide $(\mathrm{NaOH})$ solution was put on a magnetic stirrer at $70^{\circ} \mathrm{c}$ and waited till temperature sets and then rotation of the stirrer was started. Zinc nitrate solution was added by using a burette dropwise very slowly at a speed of 1 drop in 3 seconds and continued stirring at $70^{\circ} \mathrm{C}$ temperature. Then, this full solution was added to the alkaline solution slowly, at that moment stirring was kept continued for $3 \mathrm{hrs}$. As a result, a suspension was produced and the mixture was cooled at room temperature overnight for precipitation. Then finally the suspension was filtered \& washed with deionized water \& ethanol several times. Subsequently, the dryer was used to convert ZnO NPs in powder form at $65^{\circ} \mathrm{c}$ temperature.

\subsection{Anthelmintic Assay}

The anthelmintic assays were accomplished as per the method of Ajaiyeoba ${ }^{34,35}$ with minor modifications. ${ }^{36,37}$ For this experimental observation, adult Earthworms (Phertima posthuma) were collected from the muggy soil on the campus of NSTU, Noakhali. Then normal saline water was used on the surrounding body of Pheretima posthuma to remove all the solid or liquid waste. The length, width and weight of collected Pheretima posthuma were $3-5 \mathrm{~cm}, 0.1-0.2 \mathrm{~cm}$ and $0.8-3.04 \mathrm{~g}$ respectively and used for all standard protocols. The anatomical and physiological characteristics of the intestinal roundworm parasites of the human being are approximately the same as the adult Pheretima posthuma (earthworm) (38-40 $^{3}$ and hence were used to investigate the antihelminthic potential. Albendazole was used as a reference standard. ${ }^{41}$

$\mathrm{ZnO}$ NPs were used as a test sample and CMC solution was used as a solvent to dissolve $\mathrm{ZnO}$ nanoparticles. Then three concentrations $(10,20,40 \mathrm{mg} / \mathrm{ml})$ of CMC solution were put in an ultrasonic bath for 20 minutes to disperse the test sample solution completely. After that albendazole (a reference drug) dissolved in CMC solution to make a solution which concentrations were $10,20,40 \mathrm{mg} / \mathrm{ml}$. This reference solution was also put in an ultrasonic bath for 20 minutes to completely disperse the solution. In this experiment, seven Petri-dishes were used in which two earthworms (Pheretima posthuma) were put in every dish. Besides, three groups (each containing two earthworms) were applied to the three concentrations $\mathrm{ZnO}$ nanoparticles of test samples and as a reference standard one group was applied in this assay. Only control solution CMC was applied on two earthworms in one petri-dish for showing its effect on earthworms (Phertima posthuma). The most important observation in this experiment was the physical change in the earthworms. So continuous observation was performed to notice any change in earthworm's body because physical change relates to movement. The time of paralysis and time for the death of worms were recorded sincerely and perfectly after ascertaining that the worms neither moved when shaken vigorously. ${ }^{42}$

\section{Results and Discussion}

\subsection{Scanning Electron Microscopy (SEM)}

To observe morphological characteristics and sizes limit of nanoparticles, SEM techniques were used. It is easily done after ZnO powder obtained. An SEM instrument (Hitachi S-3400, Japan) was used for these purposes from BCSIR, Dhaka, Bangladesh. It is mainly designed for the study of solid surface objects in which dimensional images (3D) are understood. SEM analysis using an emission current $5900 \mathrm{nA}$ at a $15 \mathrm{KV}$ voltage of different magnification ranges. SEM of ZnO nanoparticles revealed that some particles are agglomerated \& some are well defined. Besides, the complete 
separation did not occur and we also examined some particles were of small fibrous characteristics. Because of weak physical forces, the particles are held together also. In addition, plentiful edges and corners also appeared from the SEM images. Besides, agglomeration between nanoparticles and some stick, spherical, solids, and flakes like shapes were observed in the range of 5 and 20 micrometer. It also denoted that the nanoparticles are well dispersed in white powder form. The SEM analysis showed the particle size $478 \mathrm{~nm}$ to $801 \mathrm{~nm}$ in most cases; however, few particles were larger than $801 \mathrm{~nm}$ and also were smaller than $478 \mathrm{~nm}$. Smaller ones formed the aggregation of large particles and most of them are rough and irregular circular in shape. The overall scenario of these SEM images is nonhomogeneous morphology.
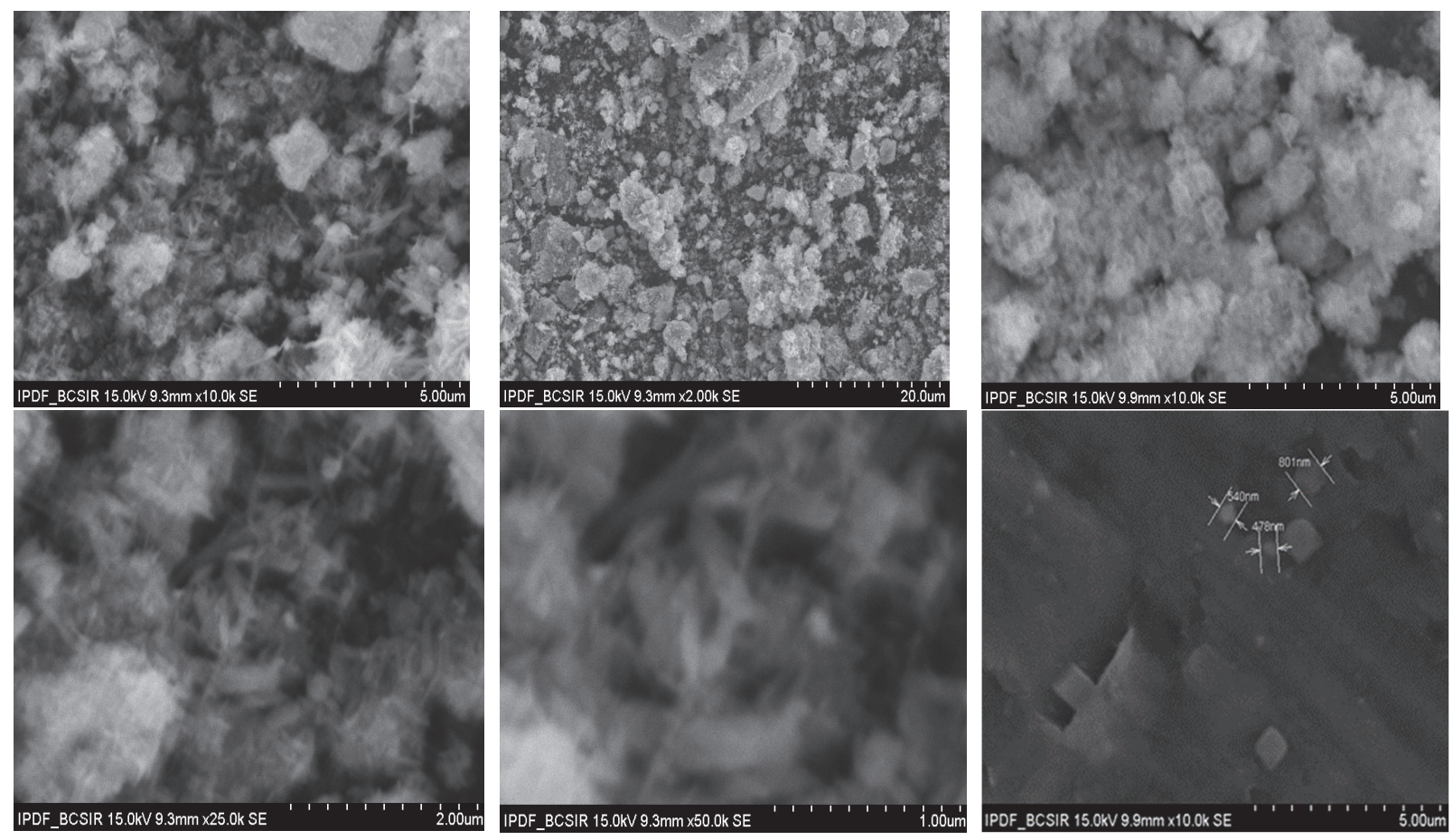

Fig. 1. SEM of $\mathrm{ZnO}$ nanoparticles at different magnifier appearance

\subsection{Annealing Temperature effect on $\mathrm{ZnO}$ nanoparticles by $U V$-Vis Spectrophotometer}

A UV-Vis spectrophotometer (1650 PC, Shimadzu) was used in the university lab for evaluating the temperature effect on $\mathrm{ZnO}$ NPs and the initial level of the synthesis of $\mathrm{ZnO}$ NPs was confirmed by collecting the absorbance on this instrument. For understanding the characterization of the absorption spectra of the samples were taken $360-380 \mathrm{~nm}$ in which the UV-vis absorption spectra of ZnO NPs prepared at different annealing temperatures are shown in Table 1. A broad absorption peak was observed in each spectrum at 360-380 $\mathrm{nm}$. Here $\mathrm{ZnO}$ nanoparticles are heated at different temperature and then the measurements of UV results are given below.

Table 1. Annealing temperature effects of $\mathrm{ZnO}$ nanoparticle in UV-vis Spectroscopy

\begin{tabular}{ccc}
\hline Temperature (Celsius) & Wavelength (nm) & Absorbance \\
\hline $400^{\circ} \mathrm{C}$ & 368 & 0.64465 \\
$500^{\circ} \mathrm{C}$ & 371.5 & 0.84366 \\
$600^{\circ} \mathrm{C}$ & 374 & 0.96722 \\
$700^{\circ} \mathrm{C}$ & 377 & 1.00308 \\
\hline
\end{tabular}

From Table 1, it is easily explained that increasing the temperature effects the wavelength and absorbance of ZnO NPs. The wavelength and absorbance are observed in an upward direction when the temperature was increasing. 


\subsection{Anthelmintic investigation result}

Earthworm (Pheretima posthuma) was kept in petri-dish in which three different concentrations $(10,20,40 \mathrm{mg} / \mathrm{ml})$ of CMC (control), Albendazole (standard) and $\mathrm{ZnO}$ nanoparticles (sample) were applied to observe the experiment. A total of 14 worms were taken in respective solutions.
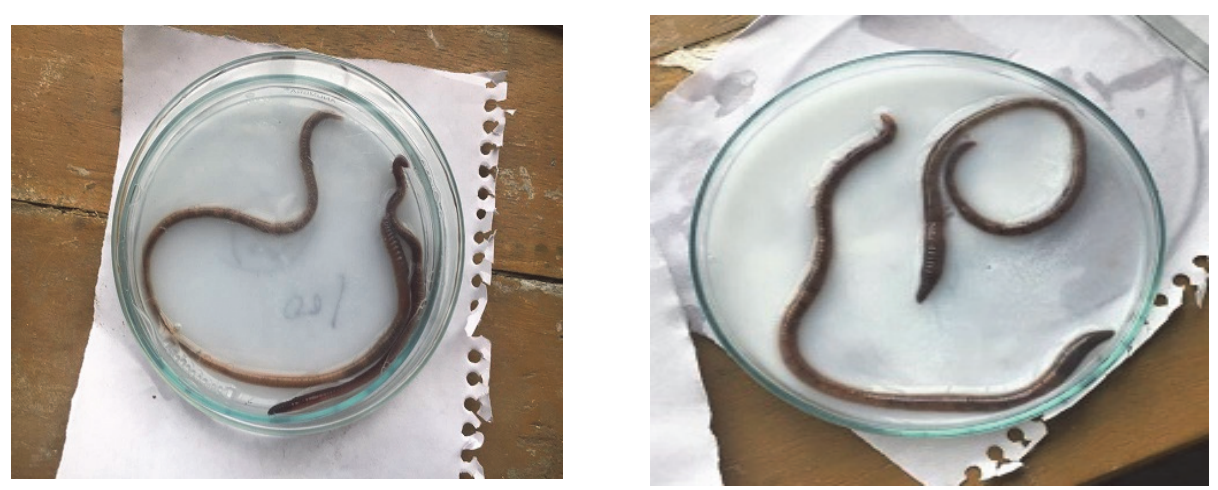

Fig. 2. Pheretima posthuma in petri-dish to observe and record paralyzed and death time.

Here the recorded PT and DT of the worm's results were shown in Table 2 below.

Table 2. Anthelmintic effects of ZnO NPS on Pheretima posthuma (Earthworms)

\begin{tabular}{lccc}
\multicolumn{1}{c}{ Groups } & $\begin{array}{c}\text { Conc. } \\
(\mathrm{mg} / \mathrm{ml})\end{array}$ & $\begin{array}{c}\text { PT (Min) } \\
\text { Mean } \pm \text { S.E.M }\end{array}$ & $\begin{array}{c}\text { DT (Min) } \\
\text { Mean } \pm \text { S.E.M }\end{array}$ \\
\hline Control ( 1\% w/w CMC) & - & - & - \\
Sample (ZnO NPS) & 10 & $330 \pm 0.33$ & Not in overnight \\
Sample (ZnO NPS) & 20 & $200 \pm 0.66$ & $450 \pm 0.43$ \\
Sample (ZnO NPS) & 40 & $35.6 \pm 0.53$ & $80 \pm 0.45$ \\
Standard (Albandazole) & 10 & Not in overnight & Not in overnight \\
Standard (Albandazole) & 20 & $410.7 \pm 0.3$ & Not in overnight \\
Standard (Albandazole) & 40 & $378.6 \pm 0.5$ & $402.3 \pm 0.4$ \\
\hline
\end{tabular}

S.E.M = Standard Error of the Mean

From Table 2, it is clear to say that the gradual increment of sample concentration of ZnO NPs provides the information about paralysis as well as the mortality incident of worms in shorter times. It is the commandments that the control solution which was prepared as a blank does not affect earthworms because of the absence of paralysis and death time showing for this solution. It is very interesting to say that at the concentration of $10 \mathrm{mg} / \mathrm{mL}$ of the sample there was no effect on the earthworm in case of death in full night and paralyzed time was so long that was 330 minutes denotable in which results were compared with the paralyzed and death time of standard was also no effect on earthworms.

From Fig. 3 (showed in below), it was understood that at the concentration of $20 \mathrm{mg} / \mathrm{ml}$ the time difference between paralysis and death time for the test sample is 250 minutes in which the standard albendazole has a higher difference because of lower concentration. But at the concentration of 40 $\mathrm{mg} / \mathrm{ml}$, the difference between paralysis and death time of earthworms for the $\mathrm{ZnO}$ nanoparticles sample is approximately 44.4 minutes which is shorter than the concentration of $20 \mathrm{mg} / \mathrm{ml}$ is comparable with the standard. For the test sample at the concentration of $40 \mathrm{mg} / \mathrm{ml}$, the paralyzed and death time was 35.6 and 80 minutes respectively. 


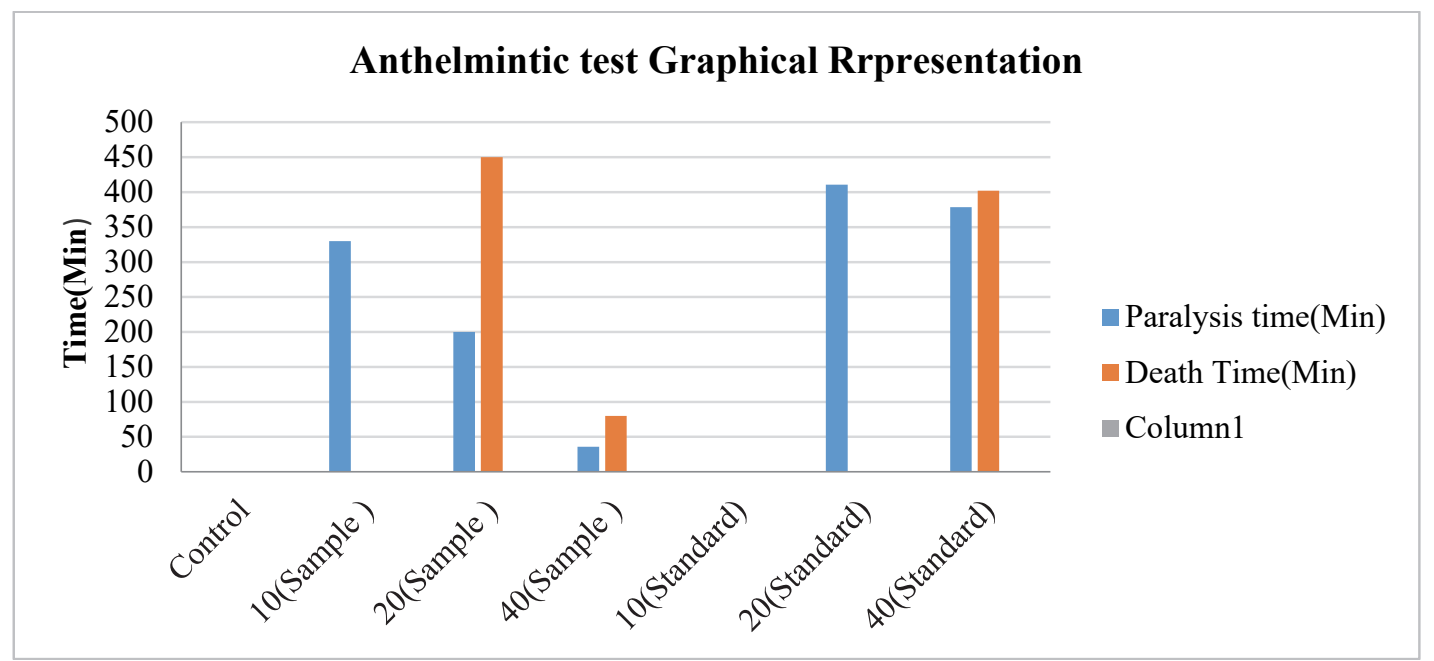

Fig. 3. A Graphical representation of anthelmintic activity of different groups

These results were compared to that of the standard drug of Albendazole at $40 \mathrm{mg} / \mathrm{mL}$ concentration showed paralysis time and death time was slightly over 378 and 402 minutes respectively. Thus at the highest dose, $40 \mathrm{mg} / \mathrm{ml}$ of sample ( $\mathrm{ZnO}$ nanoparticles) is more potent than other concentrations of this sample administered in which produced activity is comparable to the reference standard. In addition, we can establish the decision that the different concentrations of $\mathrm{ZnO}$ nanoparticles containing 10, 20, $40 \mathrm{mg} / \mathrm{ml}$ experienced dose-dependent paralysis ranging from loss of movement to loss of response to external effort, which gradually comes to death. From the above study, it was seen that the ZnO NPS showed dose (concentration) dependent anthelmintic activity showing maximum potentiality at $40 \mathrm{mg} / \mathrm{ml}$ for one type of worms as compared to standard drug albendazole. It was also observed that higher concentration $\mathrm{ZnO}$ nanoparticles produced a paralytic effect much earlier and the time taken for death was shorter for all types of worms. Therefore, further higher study and research must be taken so that the importance of the medicinal activity of these nanoparticles can be applied in the future for the betterment of human civilization and the mass people can get actual benefits from this medicinal property.

\section{Conclusions}

This current study aims to explore, analyze and prove the anthelmintic activity and some characteristics of $\mathrm{ZnO}$ nanoparticles by a simple method. From this investigation, collected and recorded data showed that $\mathrm{ZnO}$ nanoparticles exhibited excellent anthelmintic activity against Pheretima posthuma. Here one of the important facts is the synthesis process which is very easy and cost-effective to produce $\mathrm{ZnO}$ nanoparticles. This study has created a way to form new anthelmintic drugs from the $\mathrm{ZnO}$ nanoparticles. In the future, we have a plan to reinforce $\mathrm{Ag}$ doping in $\mathrm{ZnO}$ nanoparticles for a comparative study between $\mathrm{ZnO}$ NPs and $\mathrm{ZnO}: \mathrm{Ag}$ nanoparticles in case of anthelmintic activity against Pheretima posthuma. However, the further experiment is required on the human-based model to establish this finding for potential therapeutic effects. The wormicidal activity of $\mathrm{ZnO}$ nanoparticles against Pheretima posthuma suggests that they are also considered effective activity against parasitic diseases of humans. So, it can be said that $\mathrm{ZnO}$ gives a strong anthelmintic effect.

\section{Acknowledgements}

The authors are indebted to the Department of Applied Chemistry and Chemical Engineering, NSTU and BCSIR, Bangladesh for the laboratory support of this research work. 


\section{References}

1. Li, L. Z., Zhou, D. M., Peijnenburg, W. J., Van Gestel, C. A., Jin, S. Y., Wang, Y. J., and Wang, P. (2011) Toxicity of zinc oxide nanoparticles in the earthworm, Eisenia fetida and subcellular fractionation of Zn. Environ. Int., 37(6), 1098-1104.

2. Stoimenov, P. K., Klinger, R. L., Marchin, G. L., and Klabunde, K. J. (2002) Metal oxide nanoparticles as bactericidal agents. Langmuir, 18(17), 6679-6686.

3. Fu, G., Vary, P. S., and Lin, C. T. (2005) Anatase TiO2 nanocomposites for antimicrobial coatings. $J$. Phys. Chem. B, 109(18), 8889-8898.

4. Yamamoto, O. (2001) Influence of particle size on the antibacterial activity of zinc oxide. Int. J. Inorg. Mater., 3(7), 643-646.

5. Yamamoto, O., Nakakoshi, K., Sasamoto, T., Nakagawa, H., and Miura, K. (2001) Adsorption and growth inhibition of bacteria on carbon materials containing zinc oxide. Carbon, 39(11), 1643-1651.

6. Yamamoto, O., and Sawai, J. (2001) Preparation and characterization of novel activated carbons with antibacterial function. Bull. Chem. Soc. Jpn., 74(9), 1761-1765.

7. Roselli, M., Finamore, A., Garaguso, I., Britti, M. S., and Mengheri, E. (2003) Zinc oxide protects cultured enterocytes from the damage induced by Escherichia coli. J. nutr., 133(12), 4077-4082.

8. Darezereshki, E., Alizadeh, M., Bakhtiari, F., Schaffie, M., and Ranjbar, M. (2011) A novel thermal decomposition method for the synthesis of $\mathrm{ZnO}$ nanoparticles from low concentration $\mathrm{ZnSO} 4$ solutions. Appl. Clay Sci., 54(1), 107-111.

9. Tari, O., Aronne, A., Addonizio, M. L., Daliento, S., Fanelli, E., and Pernice, P. (2012) Sol-gel synthesis of $\mathrm{ZnO}$ transparent and conductive films: A critical approach. Sol. Energy Mater. Sol. Cells, 105, 179186.

10. Schmitt, R. F., Allen, J. W., and Wright, R. (2001) Rapid design of SAW oscillator electronics for sensor applications. Sens. Actuators, B: Chem., 76(1-3), 80-85.

11. Kamat, P. V., Huehn, R., and Nicolaescu, R. (2002) A "sense and shoot" approach for photocatalytic degradation of organic contaminants in water. J. Phys. Chem. B, 106(4), 788-794.

12. Sharma, P., Sreenivas, K., and Rao, K. V. (2003) Analysis of ultraviolet photoconductivity in ZnO films prepared by unbalanced magnetron sputtering. J. Appl. Phys., 93(7), 3963-3970.

13. Jun, W., Changsheng, X., Zikui, B., Bailin, Z., Kaijin, H., and Run, W. (2002) Preparation of ZnO-glass varistor from tetrapod $\mathrm{ZnO}$ nanopowders. Mater. Sci. Eng., B, 95(2), 157-161.

14. Hames, Y., Alpaslan, Z., Kösemen, A., San, S. E., and Yerli, Y. (2010) Electrochemically grown ZnO nanorods for hybrid solar cell applications. Sol. Energy, 84(3), 426-431.

15. Topoglidis, E., Cass, A. E., O'Regan, B., and Durrant, J. R. (2001) Immobilization and bioelectrochemistry of proteins on nanoporous $\mathrm{TiO}_{2}$ and $\mathrm{ZnO}$ films. J. Electroanal. Chem., 517(1-2), 20-27.

16. Cheng, X. L., Zhao, H., Huo, L. H., Gao, S., and Zhao, J. G. (2004) ZnO nanoparticulate thin film: preparation, characterization and gas-sensing property. Sens. Actuators, B: Chem., 102(2), 248-252.

17. Gao, P. X., Ding, Y., Mai, W., Hughes, W. L., Lao, C., and Wang, Z. L. (2005) Conversion of zinc oxide nanobelts into superlattice-structured nanohelices. Science, 309(5741), 1700-1704.

18. Huang, H. M., Mao, S., Feick, H., Yan, H., Wu, Y., Kind, H., Weber, E., Russo, R., and Yang, P. (2001) Room-temperature ultraviolet nanowire nanolasers. Science, 292 (5523), 1897-1899.

19. Yahya, N., Daud, H., Tajuddin, N. A., Daud, H. M., Shafie, A., and Puspitasari, P. (2010) Application of $\mathrm{ZnO}$ nanoparticles EM wave detector prepared by sol-gel and self-combustion techniques. J. Nano Res., 11 (25-34), 1661-9897.

20. Charinpanitkul, T., Faungnawakij, K., and Tanthapanichakoon, W. (2008) Review of recent research on nanoparticle production in Thailand. Adv. Powder Technol., 19(5), 443-457.

21. Yu, W., Li, X., and Gao, X. (2005) Catalytic synthesis and structural characteristics of high-quality tetrapod-like $\mathrm{ZnO}$ nanocrystals by a modified vapor transport process. Cryst. Growth Des., 5(1), 151155.

22.Zak, A. K., Abrishami, M. E., Majid, W. A., Yousefi, R., and Hosseini, S. M. (2011) Effects of annealing temperature on some structural and optical properties of $\mathrm{ZnO}$ nanoparticles prepared by a modified solgel combustion method. Ceram. Int., 37(1), 393-398. 
23. Raoufi, D. (2013) Synthesis and microstructural properties of $\mathrm{ZnO}$ nanoparticles prepared by precipitation method. Renew. Energy, 50, 932-937.

24. Lanje, A. S., Sharma, S. J., Ningthoujam, R. S., Ahn, J. S., and Pode, R. B. (2013) Low temperature dielectric studies of zinc oxide $(\mathrm{ZnO})$ nanoparticles prepared by precipitation method. Adv. Powder Technol., 24(1), 331-335.

25. Chen, C., Liu, P., and Lu, C. (2008) Synthesis and characterization of nano-sized ZnO powders by direct precipitation method. Chem. Eng. J., 144(3), 509-513.

26. Hu, X. L., Zhu, Y. J., and Wang, S. W. (2004) Sonochemical and microwave-assisted synthesis of linked single-crystalline $\mathrm{ZnO}$ rods. Mater. Chem. phys., 88(2-3), 421-426.

27. Hong, R. Y. (2005) Nanosized $\mathrm{ZnO}$ prepared by microwave homogeneous precipitation and its photocatalytic property. Chin. J. Process Eng., 5, 693-697.

28. Sato, T., Tanigaki, T., Suzuki, H., Saito, Y., Kido, O., Kimura, Y., and Kaneko, S. (2003) Structure and optical spectrum of ZnO nanoparticles produced in RF plasma. J. Cryst. Growth, 255(3-4), 313-316.

29. Zhai, H. J., Wu, W. H., Lu, F., Wang, H. S., and Wang, C. (2008) Effects of ammonia and cetyltrimethylammonium bromide $(\mathrm{CTAB})$ on morphologies of $\mathrm{ZnO}$ nano-and micromaterials under solvothermal process. Mater. Chem. phys., 112(3), 1024-1028.

30. Suleiman, M. M., Mamman, M., Aliu, Y. O., \& Ajanusi, J. O. (2005) Anthelmintic activity of the crude methanol extract of Xylopia aethiopica against Nippostrongylus brasiliensis in rats. Veterinarski arhiv, 75(6), 487.

31. Khan, Y. A., Singh, B. R., Ullah, R., Shoeb, M., Naqvi, A. H., and Abidi, S. M. (2015) Anthelmintic effect of biocompatible zinc oxide nanoparticles ( $\mathrm{ZnO}$ NPs) on Gigantocotyle explanatum, a neglected parasite of Indian water buffalo. PloS One, 10(7).

32. Gusatti, M., Rosário, J. A., Barroso, G. S., Campos, C. E., Riella, H. G., and Kunhen, N. C. (2014) Synthesis of $\mathrm{ZnO}$ nanostructures in low reaction temperature. Chem. Eng. Transactions, Italy, 17, 10171022.

33. Lanje, A. S., Sharma, S. J., Ningthoujam, R. S., Ahn, J. S., and Pode, R. B. (2013) Low temperature dielectric studies of zinc oxide $(\mathrm{ZnO})$ nanoparticles prepared by precipitation method. Adv. Powder Technol., 24(1), 331-335.

34. Ajaiyeoba, E. O., Onocha, P. A., and Olarenwaju, O. T. (2001) In vitro anthelmintic properties of Buchholzia coriaceae and Gynandropsis gynandra extracts. Pharm. biol., 39(3), 217-220.

35. Kumar, A., Lakshman, K., Jayaveera, K. N., Nandeesh, R., Manoj, B., and Ranganayakulu, D. (2010) Comparative in vitro anthelmintic activity of three plants from the Amaranthaceae family. Arch. Biol. Sci., 62(1), 185-189.

36. Kokate, C. K. (1999) Practical Pharmacognosy, 4th Ed., Vallabha Prakashan, New Delhi.

37. Deore, S.L., Khadabadi, S. S., Kamdi, K. S., Ingle, V. P., Kawalkar, N.G., Sawarkar, P.S., Patil, U.A., and Vyas, A.J. (2009) In vitro anthelmintic activity of Cassia tora. Int. J. ChemTech Res., 1(2), 177-179.

38. Vidyarthi, R. D. (1977) A Text Book of Zoology, 14th Ed., S. Chand and Co, New Delhi.

39. Jung, R. C. (1982) Update I-Harrison's Principles of Internal Medicine with CME Examination. Am. J. Trop. Med. Hyg., 31(1), 172-173.

40. Vigar, Z. (1984) Atlas of Medical Parasitology, 2nd Ed., PG Publishing House, Singapore.

41. Shivkar, Y. M., and Kumar, V. L. (2003) Anthelmintic activity of latex of Calotropis procera. Pharm. biol., 41(4), 263-265.

42. Islam, M. S., Moghal, M. M., Ahamed, S. K., Ahmed, J., \& Islam, M. A. (2013) A study on cytotoxic and anthelmintic activities of crude extract of leaves of Clerodendrum viscosum. Int. Res. J. Pharm., 4(1), 99-102.

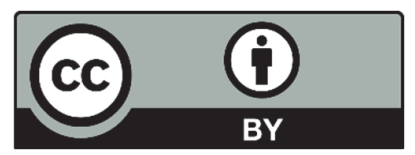

(C) 2021 by the authors; licensee Growing Science, Canada. This is an open access article distributed under the terms and conditions of the Creative Commons Attribution (CC-BY) license (http://creativecommons.org/licenses/by/4.0/). 